Int. J. Dev. Biol. 51: 241-246 (2007)

doi: $10.1387 / \mathrm{ijdb} .062220 \mathrm{em}$

Developmental Expression Pattern

\title{
Zebrafish spata2 is expressed at early developmental stages
}

\author{
ENRICO MORO ${ }^{1, \#, ~ C L A U D I O ~ M A R A N ³, \#, ~ M . ~ L I L I A N A ~ S L O N G O 3 ~}{ }^{3}$, FRANCESCO ARGENTON ${ }^{1}$, STEFANO TOPPO ${ }^{2}$ \\ and MAURIZIO ONISTO ${ }^{3, *}$ \\ ${ }^{1}$ Dept. of Biology, ${ }^{2}$ Dept. of Biological Chemistry and ${ }^{3}$ Dept. of Experimental Biomedical Sciences, University of Padua, Padova, Italy
}

\begin{abstract}
Spata2 (spermatogenesis-associated protein 2) was originally described as a novel gene involved in the spermatogenic process. In this study, we cloned a potential zebrafish spata2 orthologue. The consensus open reading frame (1650 bp) encodes a polypeptide of 550 amino acids which shares $37 \%$ identity with the human SPATA2. Bioinformatic analysis reveals a small pattern PW [KR] KE [YF][RK] which seems to be of particular interest in the light of its strong conservation between SPATA2 and the recently discovered TAMO protein of $D$. melanogaster. RTPCR analysis in adult zebrafish tissues revealed that spata2 mRNA has a broad distribution. Whole-mount in situ hybridization demonstrated that spata2 transcripts are maternally derived and becomes strongly localized in the central nervous system at early developmental stages. From 5 dpf, spata2 expression becomes detectable in the gut and pronephric duct epithelium, suggesting a wide tissue function during vertebrate development.
\end{abstract}

KEY WORDS: spata2, zebrafish (Danio rerio), whole-mount in situ hybridization

pd1 was initially identified and cloned as a novel human gene from testis cDNA library (Graziotto et al., 1999). The rat orthologue of human pd1 was further cloned and, according to the Gene Nomenclature Committee, was renamed spata2 (spermatogenesis-associated protein 2) gene on the basis of expression analysis performed on rat testis at different testicular developmental stages (Onisto et al., 2000). The analysis of the human and rat cDNA sequences disclosed an open reading frame for a protein of 520 and 511 amino acids respectively, with an overall identity of $85 \%$. High expression spata2levels have been detected in the brain, both in human and rodents, whereas less abundant transcripts were identified by virtue of RT-PCR experiments in skeletal muscle and kidneys (Onisto et al., 2001). Using a bioinformatic approach, it has been predicted that SPATA2 protein is highly hydrophilic, contains a cluster of 17 cysteins at its $\mathrm{C}$-terminus and shares a significant similarity with the recently characterized Drosophila melanogasterTAMO protein at the N-terminus (Minakhina et al., 2003).

The promoter region and the structural organization of the human spata2 gene were also determined showing that this gene is composed of three exons and two introns spanning a region of about $12.1 \mathrm{~kb}$ localized at $20 \mathrm{q} 13.13$ (Slongo et al., 2003). The transient expression of chimeric SPATA2-GFP in HL-TAT cells (Onisto et al., 2001) revealed that spata2 has a nuclear localization, but a clear function at the cellular level has not elucidated so far.

Having given the major technical drawbacks in using rodents as animal models to address our investigation of SPATA2 function, we decided to identify a potential orthologue in the teleost fish Danio rerio. This animal has become widely used as a genetic tool to uncover specific functions of unknown proteins (Dooley and Zon, 2000; Rubinstein, 2003). Its transparency at early developmental stages together with the easy manipulation and high reproductive capability makes it an ideal animal system for molecular studies. Therefore, we carried out a systematic search of potential spata2 gene in public zebrafish databases.

Here we report the cloning and characterization of a $2905 \mathrm{bp}$ cDNA sequence which represents a candidate zebrafish orthologue of the human spata2 gene. By means of whole-mount in situ analysis we further show its spatiotemporal expression

\footnotetext{
Abbreviations used in this paper:aa, aminoacid; BCIP, bromo-4-chloro-3-indolyl phosphate; bp, base pair; CNS, central nervous system; cDNA, complementary DNA; Dig, digoxygenin; dpf, days post fertilization; EDTA, ethylenediaminetetra-acetic acid; hpf, hours post fertilization; kb, kilobase; NBT, nitro blue tetrazolium; nt, nucleotide; PCR, polymerase chain reaction; RACE, rapid amplification of cDNA ends; RT-PCR, reverse transcriptasepolymerase chain reaction; spata, spermatogenesis-associated protein; TAE, tris-acetic acid-EDTA; UTR, untraslated region.
}

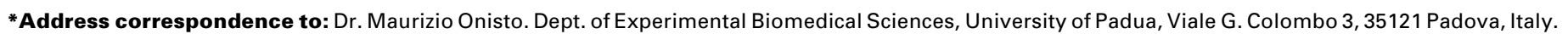
Fax: 0039-049-827-6097.e-mail: maurizio.onisto@unipd.it
}

\# Note: These authors contributed equally to this paper. 


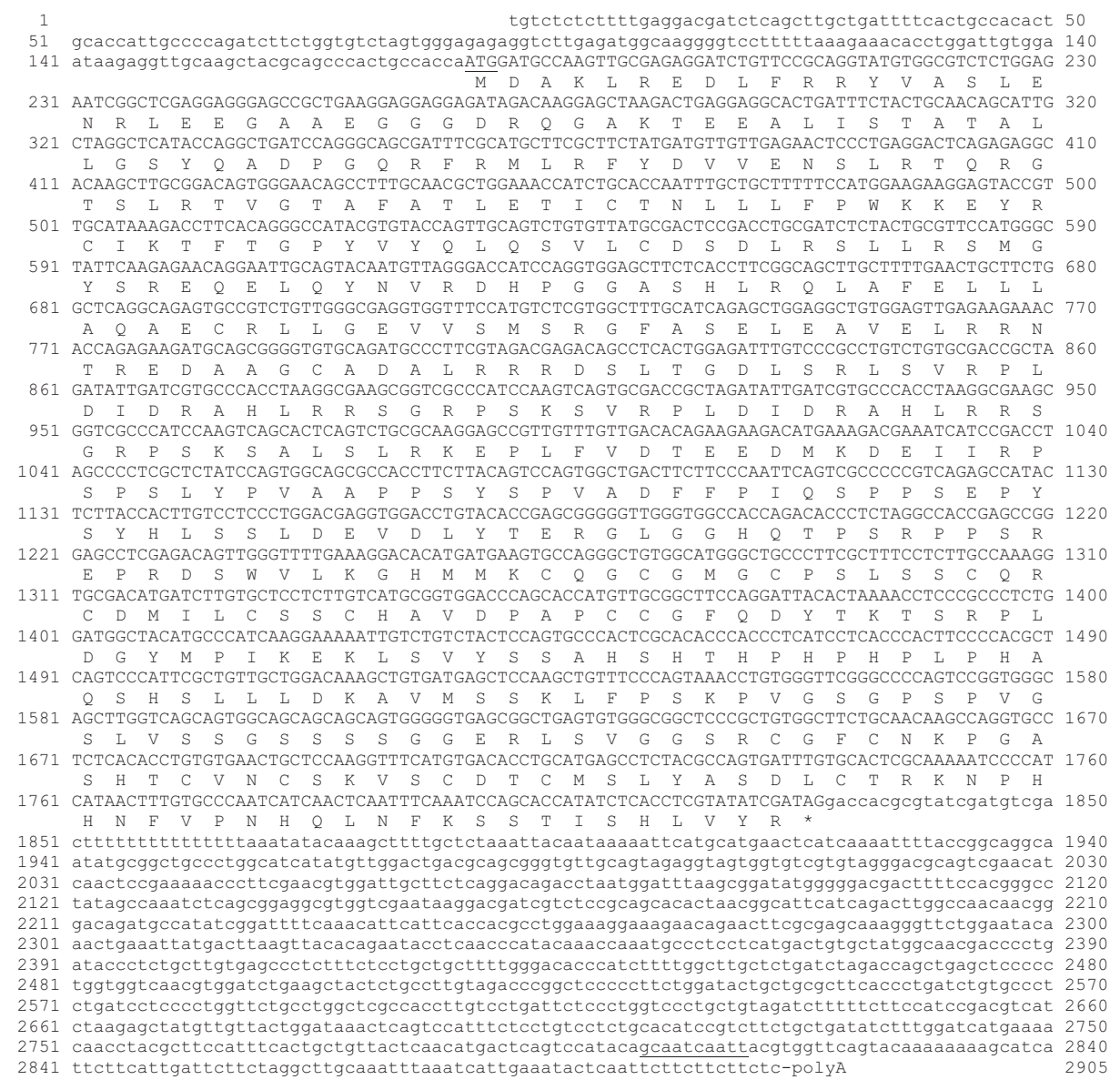

Fig. 1. Nucleotide sequence of zebrafish spata2 cDNA. The 5'-UTR and 3'-UTR are shown in lowercase letters and the coding region (nucleotides 177-1830) in uppercase letters. The stop codon is asterisked. A putative polyadenylation signal is underlined. The deduced amino acid sequence (540 amino acids) is also shown below the nucleotide sequence.

during early developmental stages.

\section{Isolation and characterization of zebrafish spata2 cDNA sequence}

Starting from the amino acid sequence of human SPATA2 we have identified, by PSI-BLAST alignment, the potential orthologue in zebrafish. Using the Ensembl zebrafish server, we retrieved the relative nucleotide sequence (Ensembl Transcript ID ENSDART00000034839) classified as similar to spata2gene. Since the deposited sequence in Ensembl Database was not completed, we sought to confirm the spata2nucleotide sequence and to obtain the full-length CDNA. cDNA was generated by means of a RACE-PCR strategy. Using spata2 gene-specific primers, we obtained 5' and 3' RACE fragments which were assembled to generate a complete cDNA sequence (GenBank Accession No. DQ869310). The total length of the cDNA sequence, as shown in Fig. 1, is 2905 bp excluding the poly (A) tail. Sequence analysis revealed an ORF of $1650 \mathrm{bp}$ encoding a protein of 550 amino acids. The length of 5' and 3' UTRs is $176 \mathrm{bp}$ and 1076 bp respectively.

The translation start codon was assigned to the first in frame ATG that appeared downstream at a stop codon TGA at bases 96 to 98. Furthermore, this first ATG position is in agreement with
Kozak's consensus sequence.

Compared to the Ensembl transcript ID ENSDART00000034839, our spata2 sequence contains a 162 bp longer region in the coding sequence.

We found that zebrafish SPATA2 protein shares $37 \%$ and $36 \%$ identity in amino acid sequence with H.sapiens (GenBank Accession No. U28164) and R.norvegicus (GenBank Accession No.AF123651) SPATA2 respectively.

\section{Bioinformatic and amino acid se- quence analysis of zebrafish SPATA2}

SPATA2 proteins of $D$. rerio and $T$. rubripes seem to differ from the general consensus of other proteins belonging to this family (Fig. 2). The Nterminus is slightly longer accounting for a predicted longer alpha helix, whereas the region from 220 to 480 residues varies in length and composition, showing a more manifest divergence and, overall less conservation. Conservation is again seen in the final C-terminal residues that are well aligned. Several in silico analyses suggest that SPATA2 may be a multidomain protein. Despite the fact that no experimental evidence supports this hypothesis, some details should be pointed out. The first 220 amino acids show an ordered secondary structure topology that is mainly alpha helix and it is the only portion of the protein that shares an evident similarity to TAMO protein (Minakhina et al., 2003), as will be discussed further. The remaining portion of the protein has a central region from aa 220 to aa 480 that does not seem to be conserved. This lack of conservation is both due to mismatches and deletions that are reported as dots in the multiple alignment in Fig. 2. From aa 480 to aa 550 it is possible to observe again a high sequence conservation along this protein family. Both secondary structure and disorder predictions have also detected a wide region starting from residue 220 up to the end of the protein with few secondary structures and highly disordered segments confirmed by the presence of prolines and charged amino acids. In addition, this region, if compared with the $\mathrm{N}$-terminus, contains a high content of cysteines that may play an important role in either keeping the tertiary structure of this domain tight or interacting with other proteins in signal pathways forming inter/intra chain disulfide bonds. Long disorder regions are, generally, involved in communication and interaction processes (Dyson and Wright, 2005) suggesting that the C-terminus of SPATA2 may play a similar functional role.

As already detected, the only evident similarity of SPATA2 is with TAMO protein. SPATA2 shows a similarity of over $43 \%$ in the first 174 residues of the $\mathrm{N}$-terminal region to the $\mathrm{N}$-terminus of TAMO protein (Fig. 3) which, in addition, shares the same predicted secondary structure topology with SPATA2. TAMO has 

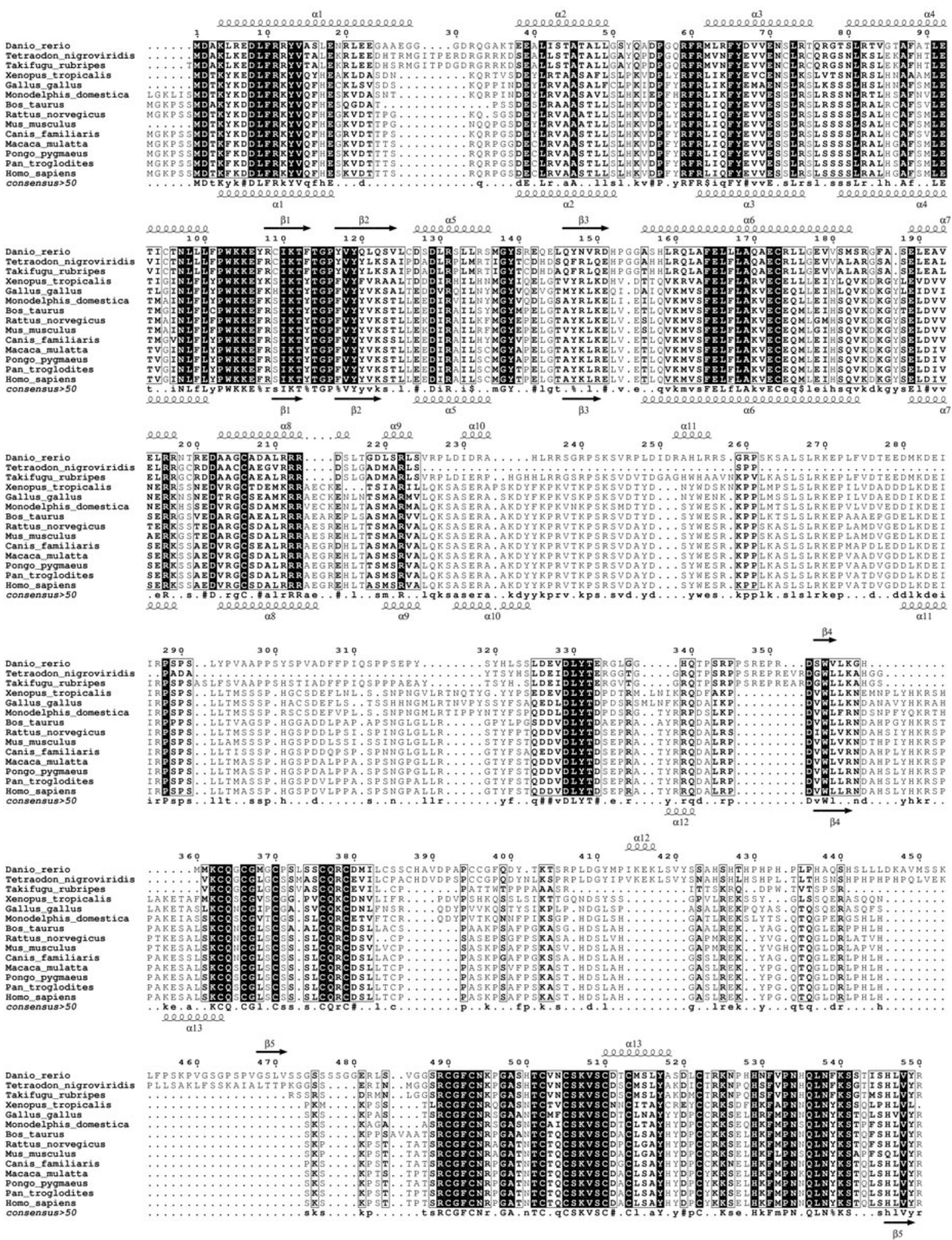

Fig. 2. Multiple sequence alignment of 13 SPATA2 proteins and their $\mathbf{5 0} \%$ consensus threshold. The final alignment includes SPATA2 from D. rerio and 12 extracted proteins whose accession numbers are reported here. Sequences from Ensembl genome database are: T. rubripes NEWSINFRUP00000179181, X. tropicalis ENSXETP00000051789 (gene prediction), M. domestica ENSMODP00000020381 and P. troglodites ENSPTRP00000023412. From GenBank: G. gallus CAG32546, B. taurus XP_608202.2, R. norvegicus AAK61814, M. musculus NP_739562, C. familiaris XP_543047, M. mulatta XP_001098381, P. pigmaeus CAH91094 and H. sapiens CAB46029. Secondary structure predictions of D. rerio (top of the alignment) and $\mathrm{H}$. sapiens (bottom of the alignment) are shown. 


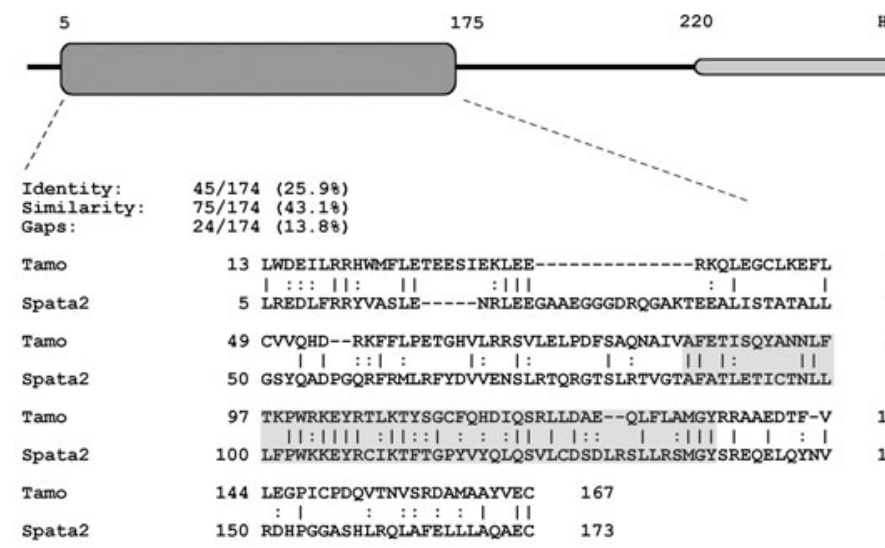

been demonstrated to be a protein involved in nuclear import machinery during oogenesis in $D$. melanogaster. Nonetheless, no particular functional properties of the $\mathrm{N}$-terminus of TAMO have been ascertained (Minakhina et al., 2003) but strong local similarities (up to $62 \%$ highlighted in gray in the alignment in Fig. 3 ) to SPATA2 suggest a putative important role of this region. Different length patterns, designed on the most conserved portion of this particular region (data not shown), have been tested against protein and domain databanks but no significant hits have been retrieved. The small pattern $P W[K R] K E[Y F][R K]$ seems of particular interest due to its strong conservation between SPATA2 and TAMO proteins. It is located in a putative loop region from 100

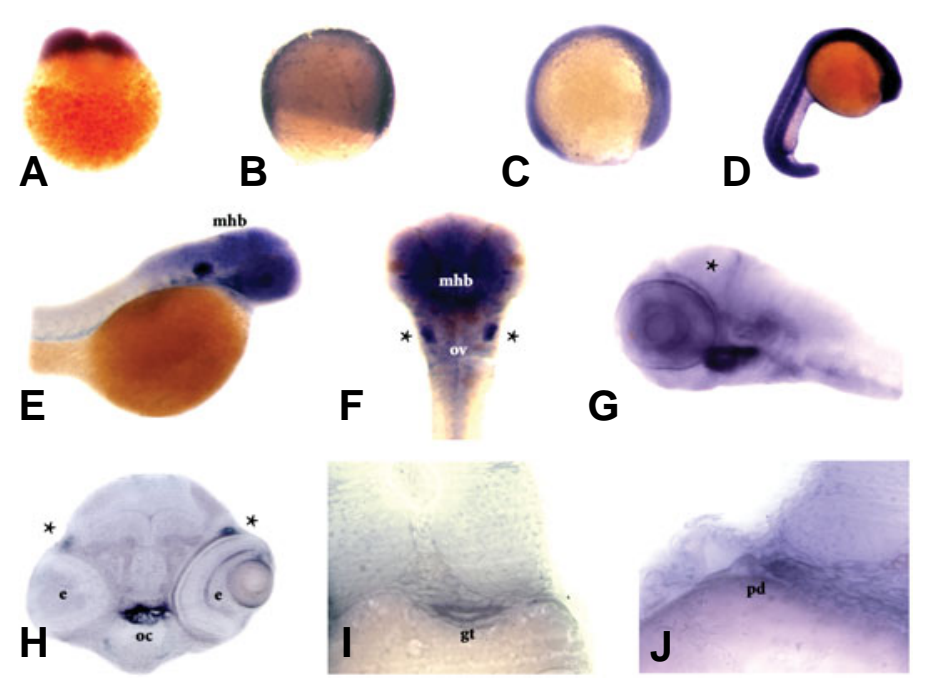

to 110 residues that connects an alpha helix to a beta strand (Fig. 3). The direct consequence of this investigation indicates that this is a peculiar signature shared between TAMO and SPATA2 protein families.

\section{Spatiotemporal expression of spata2}

To analyze the spatiotemporal expression of spata2 during early embryonic development, whole-mount in situ hybridization was performed from two-cell stage to five-day-old embryos using the antisense probe. spata2transcripts were already detected at two-cell stage, thus pointing to a maternal origin of the transcript (Fig. 4A). From the shield stage to 5-prim (24 hpf), spata2 mRNAs were ubiquitously expressed (Fig. 4 B,C,D), however by the hatching period (48 hpf) a characteristic pattern was displayed in the head with marked staining in the midbrain-hindbrain boundary and in the otic vescicles (Fig. 4 E,F). Restricted signal localization was evident at $120 \mathrm{hpf}$ in the oral cavity and in a dorsal portion of the periorbital region (Fig. $4 \mathrm{G}, \mathrm{H}$ ). More caudally spata2 expression was visible in the gut and pronephric duct luminal epithelium (Fig. $4 \mathrm{I}, \mathrm{J}$ ). By means of a detailed examination on transverse section we showed that spata2mRNA is mainly present in luminal epithelia, such as gut and pronephric duct as well as in the oral cavity. To assess the specificity of the antisense probe, a sense

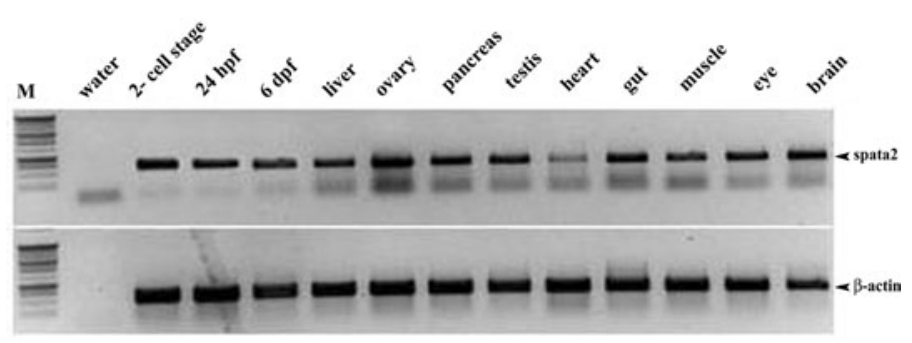

Fig. 4 (Left). Expression of zebrafish spata2 during embryonic development. spata2 mRNA was already detected at the 2-cell stage (A) and was found to be distributed ubiquitously at shield (B), 20 somite (C) and 5-prim (D) stages. At the hatching period (48 hpf), a strong signal was detected in the head, particularly at the midbrain-hindbrain boundary and in the otic vescicles (E,F). Expression become more restricted at 5 dpf in the oral cavity and in the periorbital cartilage (G,H). More caudally, vibratome sections allowed the identification of spata2 mRNA in the gut (I) and pronephric duct epithelium (J). Abbreviations: mbh, midbrain-hindbrain boundary; e, eye; oc, oral cavity; gt, gut; pd, pronephric duct.

Fig. 5 (Right). RT-PCR analysis of spata2 mRNA extracted from several adult zebrafish tissues and at different stages of development. Total RNA from each tissue was reverse-transcribed into cDNA and subsequently amplified using zebrafish spata2 and $\beta$-actin (positive control) specific primers. The expected 614 bp band was observed in all tissues showing a ubiquitous spatial expression in adult stages. spata2 was also detected at different early developmental stages (2-cell stage; 24 hpf; 6 dpf). 
probe was used in a parallel control experiment at all stages but no staining was detected in any embryo (data not shown).

The consistency of hybridization experiments was confirmed by RT-PCR expression analysis performed on cDNAs from whole zebrafish embryos at various early developmental stages (Fig. 5).

Since in adult rats spata2 orthologue exhibits a restricted pattern of tissue distribution, we further addressed the question as to whether zebrafish spata2 maintain its ubiquitous spatial expression in adult stages. As shown in Fig. 5, RT-PCR based analysis demonstrated that almost all analyzed tissues of adult fish do display a high content of spata2transcripts.

In conclusion, these results of whole-mount in situ hybridization and RT-PCR performed both in zebrafish embryos and adult tissues provide evidence that spata2 may have a broader function than previously described. The localization of its transcripts at early stages in the CNS as well as in peculiar epithelialrestricted domain in later stages suggests a function for spata2in zebrafish development. Further analysis is ongoing in order to improve knowledge on the role of spata2.

\section{Experimental Procedures}

\section{Zebrafish embryo maintenance}

Zebrafish were raised and maintained under standard laboratory conditions at $28^{\circ} \mathrm{C}$ (Westerfield et al., 1995). Embryos at different stages were collected and stored in $0.003 \%$ phenyl-thiourea (PTU) (Sigma). This solution was added to the embryos to block pigment formation in order to improve visualization of RNA during in situ hybridization. The embryo stages were identified by morphological features and the corresponding embryos were fixed in $4 \%$ paraformaldehyde.

\section{Cloning and sequencing of the zebrafish spata2 gene}

Total RNA was isolated from pooled embryos at various developmental stages using the "TRIzol ${ }^{\circledR}$ Reagent" (Invitrogen) according to the manufacturer's instructions.

By means of the SMART RACE cDNA amplification kit (Clontech) we isolated the full-length of zebrafish spata2 cDNA. Using $1 \mu \mathrm{g}$ of total $\mathrm{mRNA}$, the reverse transcription reaction was performed for $90 \mathrm{~min}$ at $42^{\circ} \mathrm{C}$ in a final volume of $10 \mu \mathrm{l}$ in the presence of SMART IITM A Oligonucleotide and $200 \mathrm{U}$ of Powerscript ${ }^{\mathrm{TM}}$ reverse transcriptase, $5 \mathrm{x}$ First-Strand Buffer $(250 \mathrm{mM}$ Tris- $\mathrm{HCl}, \mathrm{pH}$ 8.3; $375 \mathrm{mM} \mathrm{KCl} ; 30 \mathrm{mM}$ $\mathrm{MgCl}_{2}$ ), $10 \mathrm{mM}$ each of dNTPs and $20 \mathrm{mM}$ dithiothreitol. RACE-PCR reactions were performed using two spata2 gene-specific primers (forward 5'-AGTGGCTGACTTCTTCCCA-3' and reverse 5'TGTGTGAACTGCTCCAAGG-3') and a universal anchor primer (5'CTAATACGACTCACTATAGGGC-3') complementary to the adaptor ligated to both ends of the ds cDNA, according to the manufacturer's instructions. Amplification was performed for 25 cycles as follows: $30 \mathrm{sec}$ denaturation at $94^{\circ} \mathrm{C}, 30 \mathrm{sec}$ primer annealing at $68^{\circ} \mathrm{C}$ and $3 \mathrm{~min}$ extension at $72^{\circ} \mathrm{C}$. The PCR product was electrophoresed on a $1 \%$ agarose gel in $1 \times$ TAE buffer $(50 \mathrm{mM}$ Tris- $\mathrm{HCl}, \mathrm{pH} 8.0 ; 20 \mathrm{mM}$ sodium acetate; $2 \mathrm{mM} \mathrm{Na}{ }_{2} E D T A$ ) and ethidium bromide stained. The PCR product was cloned directly into pCR $^{\circledR}$ II-TOPO ${ }^{\circledR}$ Vector (TOPO TA Cloning ${ }^{\circledR}$ system, Invitrogen) and sequenced on both strands using Big Dye terminator v3.1 protocol on ABI PRISM 310 Genetic Analyzer (Applied Biosystems).

\section{Bioinformatic analysis of zebrafish spata2}

Sequences of SPATA2 were searched for using PSI-BLAST (Altschul et al., 1997) vs. non-redundant database. Sequences annotated as putative spata2 genes were extracted and enriched with sequences coming from Ensembl database of genome projects (http:// www.ensembl.org). The multiple alignment was performed by using MUSCLE (Edgar, 2004) and manual edited to identify blocks of identities among sequences. The final version of the alignment figure was prepared using Espript (Gouet et al., 2003). The secondary structures of proteins were predicted using the consensus method (Albrecht et al., 2003) whereas prediction of disorder regions was performed using a similar approach applying state-of-the-art methods such as DISOPRED (Ward et al., 2004) and SPRITZ (Vullo et al., 2006). The presence of functional domains was searched against Pfam database (Finn et al., 2006), PROSITE (Hulo et al., 2006) and InterPRO (Mulder et al., 2005). Pattern search of putative functional signatures extracted from the conserved regions of the multiple alignment was performed using ScanProsite (de Castro et al., 2006). Polyadenylations site was predicted by means of Hcpolya (http://www.itb.cnr.it/sun/webgene/) and POLYAH (www.softberry.com) programs.

\section{Whole-mount in situ hybridization}

spata2 antisense and sense riboprobes were synthesized from a spata2cDNA, corresponding to the entire coding sequence region (1650 bp) of zebrafish spata2 gene, using SP6 and T7 RNA polymerase respectively. Whole-mount in situ hybridization was carried out as previously described (Thisse etal., 1993). In brief, embryos were permeabilized with Proteinase $\mathrm{K}\left(10 \mu \mathrm{g} / \mathrm{ml}\right.$, Sigma) and hybridized overnight at $65^{\circ} \mathrm{C}$ with the DIG-labeled antisense or sense riboprobes. After several washes at high stringent temperature, NBT/BCIP (Roche) staining was performed according to the manufacturer's instructions.

Images were obtained by a Nikon SMZ 1500 digital camera system. For a more detailed analysis, vibratome sections were prepared from gelatine-albumine embedded embryos after the staining.

\section{Multi-tissue RT-PCR}

To reveal the tissue distribution and expression of zebrafish spata2 gene total RNA was extracted from various developmental stages and several fully developed organs and tissues of zebrafish. Total RNA was extracted from the tissues using the "TRIzol ${ }^{\circledR}$ Reagent" (Invitrogen) according to the manufacturer's instructions. Two micrograms of total RNA from each sample were used for synthesizing the first strand cDNA by means of reverse transcriptase.

The gene-specific primers d-SPATA2zebra (5'AGTGGCTGACTTCTTCCCA-3') and r-SPATA2zebra (5'CCTTGGAGCAGTTCACACA-3') were designed to amplify 614 bp fragment (from base 909 to base 1523) of spata2 gene. Amplification was performed for 35 cycles as follows: $30 \mathrm{sec}$ denaturation at $94^{\circ} \mathrm{C}, 30 \mathrm{sec}$ primer annealing at $58^{\circ} \mathrm{C}$ and $1 \mathrm{~min}$ extension at $72^{\circ} \mathrm{C}$. The PCR product was electrophoresed on a $1 \%$ agarose gel in 1 x TAE buffer $(50 \mathrm{mM}$ Tris$\mathrm{HCl}, \mathrm{pH}$ 8.0; $20 \mathrm{mM}$ sodium acetate; $2 \mathrm{mM} \mathrm{Na}_{2}$ EDTA) and ethidium bromide stained.

Positive control primers were designed according to zebrafish $\beta$-actin (GenBank Accession No. AF057040) as d- $\beta$-Actin: 5'TGTTTTCCCCTCCATTGTTGG-3' and r- $\beta$-Actin: 5'TTCTCCTTGATGTCACGGAC-3' to amplify a 558 nucleotide fragment. All primers were selected from two exons separated by one or more intronic sequences, to identify possible amplicons from contaminating genomic DNA.

\section{Acknowledgments}

This work was supported by University of Padova (ex $60 \%$ Grant) and by the European Commissions as part of the ZF-MODELS Integrated Project in the Sixth Framework Program (Contract no. LSHG-CT-2003503496).

\section{References}

ALBRECHT, M., TOSATTO, S.C., LENGAUER, T. and VALLE, G. (2003). Simple consensus procedures are effective and sufficient in secondary structure 
prediction. Protein Eng. 16(7): 459-462.

ALTSCHUL, S.F., MADDEN, T.L., SCHAFFER, A.A., ZHANG, J., ZHANG, Z., MILLER, W. and LIPMAN, D.J. (1997). Gapped BLAST and PSI-BLAST: a new generation of protein database search programs. Nucleic Acids Res. 25(17): 3389-3402.

DE CASTRO, E., SIGRIST, C.J., GATTIKER, A., BULLIARD, V., LANGENDIJKGENEVAUX, P.S., GASTEIGER, E., BAIROCH, A. and HULO, N. (2006). ScanProsite: detection of PROSITE signature matches and ProRule-associated functional and structural residues in proteins. Nucleic Acids Res.34: W362365.

DOOLEY, K. and ZON, L.I. (2000). Zebrafish: a model system for the study of human disease. Curr. Opin. Genet. Dev. 10: 252-256.

DYSON, H.J. and WRIGHT, P.E. (2005). Intrinsically unstructured proteins and their functions. Nat. Rev. Mol. Cell. Biol. 6(3): 197-208.

EDGAR, R.C. (2004). MUSCLE: a multiple sequence alignment method with reduced time and space complexity. BMC Bioinformatics. 5: 113.

FINN, R.D., MISTRY, J., SCHUSTER-BOCKLER, B., GRIFFITHS-JONES, S., HOLLICH, V., LASSMANN, T., MOXON, S., MARSHALL, M., KHANNA, A., DURBIN, R., EDDY, S.R., SONNHAMMER, E.L. and BATEMAN, A. (2006). Pfam: clans, web tools and services. Nucleic Acids Res. 34: D247-251.

GOUET, P., ROBERT, X. and COURCELLE, E. (2003). ESPript/ENDscript: Extracting and rendering sequence and $3 \mathrm{D}$ information from atomic structures of proteins. Nucleic Acids Res. 31(13): 3320-3323.

GRAZIOTTO, R., FORESTA, C., SCANNAPIECO, P., ZEILANTE, P., RUSSO, A. NEGRO, A., SALMASO, R. and ONISTO, M. (1999). cDNA cloning and characterization of PD1: a novel human testicular protein with different expressions in various testiculopathies. Exp. Cell Res. 248: 620-626.

HULO, N., BAIROCH, A., BULLIARD, V., CERUTTI, L., DE CASTRO, E., LANGENDIJK-GENEVAUX, P.S., PAGNI, M. and SIGRIST, C.J. (2006). The PROSITE database. Nucleic Acids Res. 34: D227-230.

MINAKHINA, S., YANG, J. and STEWARD, R. (2003). Tamo selectively modulates nuclear import in Drosophila. Genes Cells. 8: 299-310.

MULDER, N.J., APWEILER, R., ATTWOOD, T.K., BAIROCH, A., BATEMAN, A., BINNS, D., BRADLEY, P., BORK, P., BUCHER, P., CERUTTI, L., COPLEY, R., COURCELLE, E., DAS, U., DURBIN, R., FLEISCHMANN, W., GOUGH, J.,
HAFT, D., HARTE, N., HULO, N., KAHN, D., KANAPIN, A., KRESTYANINOVA M., LONSDALE, D., LOPEZ, R., LETUNIC, I., MADERA, M., MASLEN, J, MCDOWALL, J., MITCHELL, A., NIKOLSKAYA, A.N., ORCHARD, S., PAGNI, M., PONTING, C.P., QUEVILLON, E., SELENGUT, J., SIGRIST, C.J, SILVENTOINEN, V., STUDHOLME, D.J., VAUGHAN, R. and WU, C.H. (2005) InterPro, progress and status in 2005. Nucleic Acids Res. 33: D201-205.

ONISTO, M., GRAZIOTTO, R.,SCANNAPIECO, P., MARIN, P., MERICO, M., SLONGO, M.L. and FORESTA, C. (2000). A novel gene (PD1) with a potential role on rat spermatogenesis. J. Endocrinol. Invest. 23: 605-608.

ONISTO, M., SLONGO, M.L., GRAZIOTTO, R., ZOTTI, L., NEGRO, A., MERICO M., MORO, E. and FORESTA, C. (2001). Evidence for FSH-dependen upregulation of SPATA2 (Spermatogenesis-Associated Protein 2). Biochem. Biophys. Res. Comm. 283: 86-92.

RUBINSTEIN, A.M. (2003). Zebrafish: from disease modeling to drug discovery. Curr. Opin. Drug Discov. Dev. 6(2): 218-223.

SLONGO, M.L., ZOTTI L. and ONISTO, M. (2003). Cloning and characterization of the promoter region of human SPATA2 (Spermatogenesis-Associated Protein 2) gene. Bioch. Biophys. Acta. 1625: 192-196.

THISSE, C., THISSE, B., SCHILLING, T.F. and POSTLETHWAIT, J.H. (1993). Structure of the zebrafish snail1 gene and its expression in wild-tipe, spadetail and no tail mutant embryos. Development. 119: 1203-1215.

VULLO, A., BORTOLAMI, O., POLLASTRI, G. and TOSATTO, S.C. (2006). Spritz: a server for the prediction of intrinsically disordered regions in protein sequences using kernel machines. Nucleic Acids Res. 34: W164-168.

WESTERFIELD, M. et al. (1995). The Zebrafish Book: A Guide for the Laboratory Use of Zebrafish. Eugene Press.

WARD, J.J., SODHI, J.S., MCGUFFIN, L.J., BUXTON, B.F. and JONES, D.T. (2004). Prediction and functional analysis of native disorder in proteins from the three kingdoms of life. J. Mol. Biol. 337(3): 635-645.

Received: 13th September 2006 Reviewed by Referees: 31st October 2006 Modified by Authors and Accepted for Publication: 15th December 2006 Published Online: 4th April 2007

\section{Related previously published Int. J. Dev. Biol. articles}

See our recent Special Issue on Mammalian Reproduction and Development edited by B. Hogan at: http://www.ijdb.ehu.es/web/contents.php?vol=45\&issue=3

Developmental regulation of expression of Ran/M1 and Ran/M2 isoforms of Ran-GTPase in mouse testis. Pedro $P$ López-Casas, Luis A López-Fernández, Mario Párraga, Dora B Krimer and Jesús del Mazo. Int. J. Dev. Biol. (2003) 47: 307-310

mgm 1, the earliest sex-specific germline marker in Drosophila, reflects expression of the gene esg in male stem cells. Adrian Streit, Luca Bernasconi, Pavel Sergeev, Alex Cruz and Monica Steinmann-Zwicky. Int. J. Dev. Biol. (2002) 46: 159-166

The case of the midwife scientist. E Simpson. Int. J. Dev. Biol. (2001) 45: 513-518

The role of stem cell factor and of alternative c-kit gene products in the establishment, maintenance and function of germ cells. C Sette, S Dolci, R Geremia and P Rossi. Int. J. Dev. Biol. (2000) 44: 599-608

Requirement of protamine for maintaining nuclear condensation of medaka (Oryzias latipes) spermatozoa shed into water but not for promoting nuclear condensation during spermatogenesis. Y Shimizu, KMita, M Tamura, KOnitake and M Yamashita. Int. J. Dev. Biol. (2000) 44: 195-199 